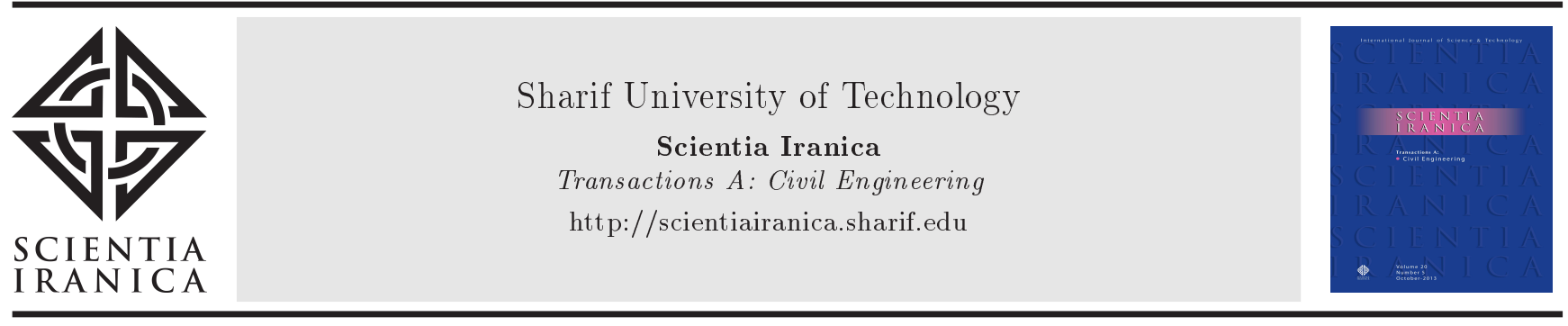

\title{
Dynamic response of concrete funicular shells with a rectangular base under impulse loads
}

\author{
H. Sabermahany, A. Vafai, and M. Mofid* \\ Department of Civil Engineering, Sharif University of Technology, Tehran, Iran.
}

Received 30 July 2017; received in revised form 4 April 2018; accepted 2 July 2018

\author{
KEYWORDS \\ Forced linear \\ vibration; \\ Doubly curved shallow \\ shells; \\ Funicular shells; \\ Lagrange equations; \\ Finite element \\ method.
}

\begin{abstract}
Funicular shells are thin, doubly curved shallow shells that are in compression under dead weight due to their shape. In this study, an analytical approach is employed to consider the forced linear vibration of concrete funicular shells with a rectangular base under impulse loads based on shallow shells theory. Two boundary conditions, simply supported and clamped, are considered. The solution is obtained by Lagrangian approach. The accuracy of the results was considered by comparing the results with those of finite element method. The results indicated that tensile stresses in addition to compressive stresses formed in funicular shells under impulse loads.

(C) 2020 Sharif University of Technology. All rights reserved.
\end{abstract}

\section{Introduction}

Reinforced concrete shells are frequently used as roofing elements. Shell structures carry load through their shape rather than material strength. Funicular shells represent a type of shells with a particular shape such that, in their membrane state, they carry a specific load by pure compression (this load is the shell's dead weight). Concrete is an appropriate material for the construction of funicular shells for two reasons. First, funicular shells are primarily subjected to compression, and concrete compressive strength is favorable. Second, concrete has the flexibility to form into any shape, which is necessary for obtaining funicular shell geometry. The performance of funicular shells subjected to dead weight is compressive; nevertheless, other types of stresses may be generated under other loads. Therefore, investigating the performance of

\footnotetext{
*. Corresponding author. Tel.: +98 21 6602-2727, Ext. 4214; Fax: +98216601-4828

E-mail addresses: hadi.saberm@ymail.com (H.

Sabermahany); vafai@sharif.edu (A. Vafai);

mofid@sharif.edu (M. Mofid)
}

doi: $10.24200 /$ sci.2018.20643 funicular shells subjected to dynamic loads appears essential. Many researchers have proposed the analysis of funicular shells under various static loads. On the other hand, for dynamic loads, no research is available. However, funicular shells with a rectangular plan are mostly shallow, and the analysis of doubly curved shallow shells under dynamic loads has been presented. For instance, Bhimaraddi [1] investigated free vibration of homogenous and laminated doubly curved shallow shells over a rectangular plan form. By applying threedimensional elasticity equations alongside the assumption where the ratio of shell thickness to its middle surface radius is negligible, as compared to unity, the governing equilibrium equations have been reduced to differential equations with constant coefficients. In fact, the complex mathematical manipulations can be avoided by reducing the governing equations to those with constant coefficients and retaining 3-D characteristics of the problem. This goes against the reduction of the governing equations to 2-D cases. The nonlinear free vibration behavior of single/doubly curved composite shallow shell panels was studied by Singh and Panda [2]. A general mathematical model, including the nonlinear higher order terms, was developed. The governing equations were determined by 
Hamilton's principle and analyzed through nonlinear Finite Element Method (FEM) steps. The effect of changing constraint conditions upon the frequencies of shallow shells with rectangular boundaries was carried out by Qatu and Leissa [3]. Three edges were completely free and the attention was given to a single edge with clamped, simply supported, and free edge conditions. The Ritz method was employed in order to obtain accurate results. It was found that releasing the constraint of the $u$-displacement component (displacement component in $x$ direction) had the largest effect on the fundamental frequencies. Abe et al. [4] presented nonlinear vibration characteristics of clamped laminated shallow shells. Moreover, both first-order shear deformation theory and classical shell theory were used. Nonlinear equations of motion were obtained by Hamilton's principle and analyzed by Galerkin's procedure. It was shown that the second mode responses were very dependent on the first mode. Amabili [5] studied geometrically nonlinear vibration of shallow shells subjected to harmonic excitation. Simply supported boundary conditions were considered. Furthermore, the nonlinear equations of motion were generated by Lagrangian approach and solved through numerical techniques. Large-amplitude free vibration of magneto-electro-elastic curved panels was studied by Shooshtari and Razavi [6]. Electrostatics and magnetostatics were considered by Gauss's laws, and the equations of motion were obtained by Donnell shell theory. Displacements and rotations were presented by trial functions. Governing nonlinear partial differential equations were transformed into nonlinear ordinary differential equations by using Galerkin method; thereafter, they were solved by the perturbation method. The analysis of funicular shells due to various static loads was carried out in many pieces of research. Vafai et al. [7] compared experimental values of membrane stresses and vertical deflections with FEM results, where good agreement was obtained. Forty-five concrete funicular shells (square bases supported at four edges) with different rises and types of reinforcement were loaded up to the failure point with a concentrated central load. It was observed that the crack and failure loads were significantly related to the rise of shells. Weber et al. [8] investigated ultimate load for concrete funicular shells by testing ten models with different geometric features. It was found that the ultimate load was dependent on the rise and thickness of the shell; by increasing the rise parameter (square of the ratio of rise to thickness), the ultimate load will also increase. Moreover, Vafai and Farshad [9] indicated that the failure load of funicular shells was affected by the age of concrete shell and the amount of reinforcement. Elangovan [10] applied the FEM in order to analyze funicular shells with clamped boundaries loaded with a uniformly distributed load. The eight-node isopara- metric elements along with five degrees of freedom for each node were used. The analysis defines the zone in which tension is generated and reinforcement is required. Rajasekaran and Sujatha [11] studied deep funicular shells using Boundary Integral Element Method (BIEM). Due to the governing equation for deep funicular shells being nonlinear, it is difficult to obtain a closed-form solution in order to determine the configuration of deep funicular shells. In addition, an incremental iterative technique along with BIEM was applied to solve the nonlinear differential equation. Lakshmikandhan et al. [12] presented the effect of the span-to-rise ratio on the performance of concrete funicular shells by applying FEM The results indicated that a reduction in the span-to-rise ratio resulted in a reduction in deflection, maximum compression, and maximum edge beam tension with improved stiffness. Similar to the previous study, Sivakumar et al. [13] considered the behavior of concrete funicular shells with a rectangular base under uniformly distributed load. A reduction in membrane stresses and deflections was discovered when the rise and thickness increased. Siddesh et al. [14] compared the performances of concrete funicular shells under concentrated load and the slabs. Analysis was performed via FEM. Six funicular shell units with a rectangular plan of $1 \times 0.7 \mathrm{~m}$, rise of 5 and $10 \mathrm{~cm}$, and thicknesses of 5,4 , and $2 \mathrm{~cm}$ were considered. Each shell unit was compared with a slab of the same thickness and dimension. The deflection of the shell models was found to be $34 \%$ to $83 \%$ less than that of the slab models. Sachithanantham [15] studied concrete funicular shells over a square plan with $0 \%$ to $16 \%$ openings under concentrated load using FEM. It was concluded that with an increase in percentage of openings, the deflection, membrane stress, and bending stress of concrete funicular shells also increased up to $800 \%, 6 \%$, and 60\%, respectively. Moreover, some other researchers considered the ultimate load along with the deflection of concrete funicular shells over a rectangular plan of different dimensions under a concentrated static load [16-19].

In this paper, a closed-form analytical solution to the forced linear vibration of concrete funicular shells with a rectangular base under impulse loads is investigated. Two boundary conditions, simply supported and clamped, are considered. Step pulse, triangular pulse, and sine pulse are considered as impulse load types that are applied to a rectangular area. The analysis is based on the expansion of each displacement component in a double Fourier series, which satisfies the boundary conditions. Strain-displacement relationships based on shallow shells theory are used to compute elastic strain energy. After computing kinetic energy, elastic strain energy, and the virtual work completed by external forces in terms of displacement components, the equations of motion are obtained by 
Lagrangian approach. Moreover, the analytical solutions to the equations of motion are developed via the modal analysis technique. The efficiency of the analysis has been examined by comparing the results with those of FEM. At the same time, the results indicate that tensile stresses in addition to compressive stresses form in funicular shells under impulse loads. On the other hand, displacements and stresses, especially tensile stresses, under dynamic impulse loads are negligible up to an amplitude of the load, which is computable. Furthermore, the effect of rise and span of the funicular shell pertaining to the time response of the shell is shown.

\section{Funicular shell surface over a rectangular ground plan}

The surface equation of a shallow funicular shell of double curvature, which carries dead weight in its membrane state by pure compression, could be given as follows [20]:

$$
\frac{\partial^{2} Z}{\partial x^{2}}+\frac{\partial^{2} Z}{\partial y^{2}}=\frac{g}{N}
$$

where $Z=f(x, y)$ is the surface equation of the funicular shell, $N$ is the desired compressive stress, and $g$ is the dead weight of the shell. The following equation, which is an approximate solution to Eq. (1), is used to define the funicular shell surface over a rectangular ground plan [12]:

$$
\begin{aligned}
Z & =\frac{5}{8} \frac{g}{N} \frac{1}{\hat{a}^{2}+\hat{b}^{2}}\left[\hat{a}^{2}-(x-\hat{a})^{2}\right]\left[\hat{b}^{2}-(y-\hat{b})^{2}\right] \\
& =H\left[1-\frac{(x-\hat{a})^{2}}{\hat{a}^{2}}\right]\left[1-\frac{(y-\hat{b})^{2}}{\hat{b}^{2}}\right]
\end{aligned}
$$

where $\hat{a}=a / 2, \hat{b}=b / 2$, and $a, b$ are the lengths of edges in $x$ and $y$ directions, respectively. $H$ is also the rise of the funicular shell. Moreover, Figure 1 shows the surface generated through Eq. (2). Displacements of an arbitrary point on the middle surface in $x, y$, and $z$ directions are $u, v$, and $w$, respectively; $w$ is taken positive inwards.

\section{Kinetic energy, strain energy, and virtual work done by external loads}

\subsection{Kinetic energy}

The kinetic energy $T$ of the shell, by neglecting rotary inertia, is given by:

$$
T=\frac{1}{2} \rho h \int_{0}^{a} \int_{0}^{b}\left[\dot{u}^{2}+\dot{v}^{2}+\dot{w}^{2}\right] d x d y,
$$

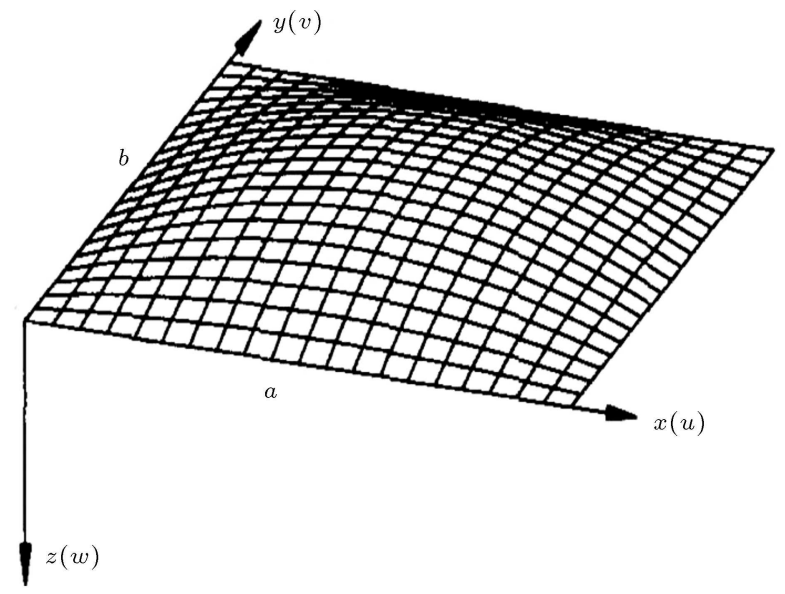

Figure 1. Funicular surface and coordinate system.

where $\rho$ is the mass density, and $h$ is the thickness of the shell. The over dot means a time derivative.

\subsection{Strain energy}

According to the shallow shells theory presented in the work of Velasov, the relationships between middle surface strains and changes in curvatures with middle surface displacement components are as follows [20]:

$$
\begin{aligned}
& \varepsilon_{x}=\frac{\partial u}{\partial x}-r w, \\
& \varepsilon_{y}=\frac{\partial v}{\partial x}-t w \\
& \gamma_{x y}=\frac{\partial u}{\partial y}+\frac{\partial v}{\partial x}-2 s w, \\
& \chi_{x}=\frac{\partial^{2} w}{\partial x^{2}} \\
& \chi_{y}=\frac{\partial^{2} w}{\partial y^{2}} \\
& \chi_{x y}=\frac{\partial^{2} w}{\partial x \partial y}
\end{aligned}
$$

where:

$$
r=\frac{\partial^{2} Z}{\partial x^{2}}, \quad t=\frac{\partial^{2} Z}{\partial y^{2}}, \quad s=\frac{\partial^{2} Z}{\partial x \partial y} .
$$

$\varepsilon_{x}, \varepsilon_{y}$, and $\gamma_{x y}$ are the middle surface strains, and $\chi_{x}$, $\chi_{y}$, and $\chi_{x y}$ are the changes in curvatures and twist of the middle surface.

The stress components $\left(\sigma_{x}, \sigma_{y}\right.$, and $\left.\sigma_{x y}\right)$ are linearly distributed across the thickness of the elastic shell. In addition, the stress resultants alongside the stress couples of the middle surface that are also named internal forces $\left(N_{x}, N_{y}\right.$, and $\left.N_{x y}\right)$ and moments $\left(M_{x}\right.$, $M_{y}$, and $\left.M_{x y}\right)$ are obtained through the integration of 
the stress distribution over the shell thickness. The relationships between stress components and internal forces, as well as moments, are [21]:

$$
\begin{aligned}
\sigma_{x}^{z} & =\frac{N_{x}}{h}+\frac{12 M_{x}}{h^{3}} z, \\
\sigma_{y}^{z} & =\frac{N_{y}}{h}+\frac{12 M_{y}}{h^{3}} z, \\
\tau_{x y}^{z} & =\frac{1}{2 h}\left(N_{x y}+N_{y x}\right)+\frac{6}{h^{3}}\left(M_{x y}+M_{y x}\right) z,
\end{aligned}
$$

where $z$ is the distance from the middle surface.

The stress resultant-strain and stress couplecurvature relations are [20]:

$$
\begin{aligned}
& N_{x}=\frac{E h}{1-\nu^{2}}\left(\varepsilon_{x}+\nu \varepsilon_{y}\right), \\
& N_{y}=\frac{E h}{1-\nu^{2}}\left(\varepsilon_{y}+\nu \varepsilon_{x}\right), \\
& N_{x y}=N_{y x}=\frac{E h}{2} \frac{1-\nu}{1-\nu^{2}} \gamma_{x y}, \\
& M_{x}=-D\left(\chi_{x}+\nu \chi_{y}\right), \\
& M_{y}=-D\left(\chi_{y}+\nu \chi_{x}\right), \\
& M_{x y}=-D(1-\nu) \chi_{x y},
\end{aligned}
$$

where $E$ is Young's modulus, $\nu$ is the Poisson's ratio, and $D=E h^{3} /\left[12\left(1-\nu^{2}\right)\right]$.

If the displacement components are calculated, the middle surface strains and changes in curvatures by Eqs. (4) to (10) and the internal forces along with the internal moments and stress components by Eqs. (11) to (19) can be obtained.

The following equation presented the strain energy with reference to the middle surface strains and changes in curvatures [21]:

$$
\begin{aligned}
U= & \frac{E h}{2\left(1-\nu^{2}\right)} \int_{0}^{a} \int_{0}^{b}\left[\varepsilon_{x}^{2}+\varepsilon_{y}^{2}+2 \nu \varepsilon_{x} \varepsilon_{y}+\frac{1-\nu}{2} \gamma_{x y}^{2}\right] d x d y \\
& +\frac{E h^{3}}{24\left(1-\nu^{2}\right)} \int_{0}^{a} \int_{0}^{b}\left[\chi_{x}^{2}+\chi_{y}^{2}+2 \nu \chi_{x} \chi_{y}\right. \\
& \left.+2(1-\nu) \chi_{x y}^{2}\right] d x d y .
\end{aligned}
$$

The first integral represents the membrane strain energy, whereas the second term indicates the bending strain energy. Through Eqs. (4) to (10), the strain energy can be presented in terms of displacement components:

$$
\begin{aligned}
U= & \frac{E h}{2\left(1-\nu^{2}\right)} \int_{0}^{a} \int_{0}^{b}\left\{\left(\frac{\partial u}{\partial x}\right)^{2}-2 \frac{\partial u}{\partial x} r w+r^{2} w^{2}+\left(\frac{\partial v}{\partial y}\right)^{2}\right. \\
& -2 \frac{\partial v}{\partial y} t w+t^{2} w^{2}+2 \nu \frac{\partial u}{\partial x} \frac{\partial v}{\partial y}-2 \nu \frac{\partial u}{\partial x} t w-2 \nu \frac{\partial v}{\partial y} r w \\
& +2 \nu r t w^{2}+\frac{1-\nu}{2}\left[\left(\frac{\partial u}{\partial y}\right)^{2}+\left(\frac{\partial v}{\partial x}\right)^{2}+4 s^{2} w^{2}\right. \\
& \left.\left.+2 \frac{\partial u}{\partial y} \frac{\partial v}{\partial x}-4 \frac{\partial u}{\partial y} s w-4 \frac{\partial v}{\partial x} s w\right]\right\} d x d y \\
& +\frac{E h^{3}}{24\left(1-\nu^{2}\right)} \int_{0}^{a} \int_{0}^{b}\left[\left(\frac{\partial^{2} w}{\partial x^{2}}\right)^{2}+\left(\frac{\partial^{2} w}{\partial y^{2}}\right)^{2}\right. \\
& \left.+2 \nu \frac{\partial^{2} w}{\partial x^{2}} \frac{\partial^{2} w}{\partial y^{2}}+2(1-\nu)\left(\frac{\partial^{2} w}{\partial x \partial y}\right)^{2}\right] d x d y . \quad(21)
\end{aligned}
$$

\subsection{Virtual work done by external loads}

The virtual work, $W$, completed by external forces is obtained as follows:

$$
W=\int_{0}^{a} \int_{0}^{b}\left(q_{x} u+q_{y} v+q_{z} w\right) d x d y
$$

where $q_{x}, q_{y}$, and $q_{z}$ are the distributed forces per unit area in $x, y$, and $z$ directions, respectively. In the present study, the applied impulsive load is distributed over a rectangular area and considered to be in the $z$ direction. The applied load area, whose center corresponds to the center of the shell, is shown in Figure 2. Furthermore, Eq. (22) can be rewritten in the following form:

$$
W=\int_{0.4 a}^{0.6 a} \int_{0.4 b}^{0.6 b} q_{z} w d x d y .
$$

The external, normal impulsive load $q_{z}$ is considered

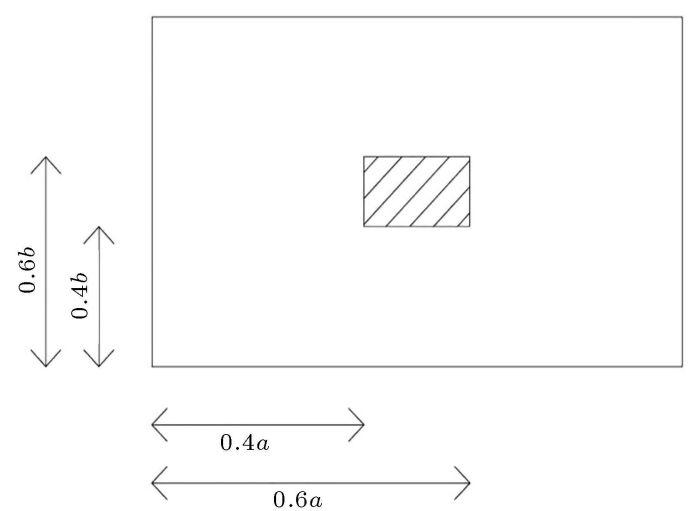

Figure 2. The area of applied load in plan. 
by three types: step pulse, triangular pulse, and sine pulse. In general:

A. Step pulse:

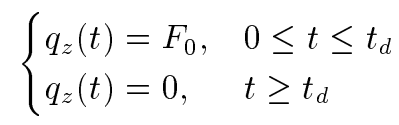

B. Triangular pulse:

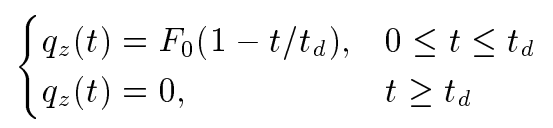

C. Sine pulse:

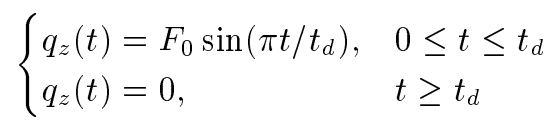

where $F_{0}$ is the magnitude of the force, and $t_{d}$ is the time duration of applying impulsive load.

\section{Boundary conditions and Fourier series of displacement components}

The following boundary conditions are considered in this study.

\section{Model A. Simply supported conditions}

For simply supported conditions where shell edges rest on diaphragms that are rigid in their own plane and flexible out of the plane, the boundary conditions are given by:

$$
\begin{aligned}
& v=w=N_{x}=M_{x}=0 \quad \text { at } \quad x=0, a, \\
& u=w=N_{y}=M_{y}=0 \quad \text { at } \quad y=0, b,
\end{aligned}
$$

where $N$ is the normal force, and $M$ is the bending moment per unit length.

The displacements $u, v$, and $w$ can be presented in the following double Fourier series, satisfying the boundary conditions:

$$
\begin{aligned}
& u(x, y, t)=\sum_{m=1}^{M} \sum_{n=1}^{N} u_{m, n}(t) \cos \left(\frac{m \pi x}{a}\right) \sin \left(\frac{n \pi y}{b}\right), \\
& v(x, y, t)=\sum_{m=1}^{M} \sum_{n=1}^{N} v_{m, n}(t) \sin \left(\frac{m \pi x}{a}\right) \cos \left(\frac{n \pi y}{b}\right), \\
& w(x, y, t)=\sum_{m=1}^{M} \sum_{n=1}^{N} w_{m, n}(t) \sin \left(\frac{m \pi x}{a}\right) \sin \left(\frac{n \pi y}{b}\right),
\end{aligned}
$$

where $m$ and $n$ are the number of expressions used in the Fourier series in $x$ and $y$ directions, respectively, and $t$ is time. In addition, $u_{m, n}, v_{m, n}$, and $w_{m, n}$ are the generalized coordinates that are unknown functions of $t$. The convergence of the solution can be considered by using different terms in Eqs. (26)-(28);

\section{Model B. Clamped edge conditions}

$$
\begin{aligned}
& u=v=w=0, \quad M_{x}=c \frac{\partial w}{\partial x} \quad \text { at } \quad x=0, a, \\
& u=v=w=0, \quad M_{y}=c \frac{\partial w}{\partial y} \quad \text { at } \quad y=0, b,
\end{aligned}
$$

where $c$ is the stiffness per unit length of the elastic and distributed rotational springs placed at four edges. Model B was developed in [22] and provides fixed edge in-plane with free rotation by $c=0$ and a perfectly clamped condition $(\partial w / \partial x=0$ and $\partial w / \partial y=0)$ obtained for $\mathrm{c} \rightarrow 8$. The displacements $u, v$, and $w$ can be presented in the following double Fourier series, which satisfy the boundary conditions:

$$
\begin{aligned}
& u(x, y, t)=\sum_{m=1}^{M} \sum_{n=1}^{N} u_{m, n}(t) \sin \left(\frac{m \pi x}{a}\right) \sin \left(\frac{n \pi y}{b}\right), \\
& v(x, y, t)=\sum_{m=1}^{M} \sum_{n=1}^{N} v_{m, n}(t) \sin \left(\frac{m \pi x}{a}\right) \sin \left(\frac{n \pi y}{b}\right), \\
& w(x, y, t)=\sum_{m=1}^{M} \sum_{n=1}^{N} w_{m, n}(t) \sin \left(\frac{m \pi x}{a}\right) \sin \left(\frac{n \pi y}{b}\right) .
\end{aligned}
$$

When $c$ is not zero, an additional potential energy is generated in the rotational springs that must be added to the elastic strain energy. This potential energy, $U_{R}$, is given by:

$$
\begin{aligned}
U_{R}= & \frac{1}{2} \int_{0}^{b} c\left\{\left[\left(\frac{\partial w}{\partial x}\right)_{x=0}\right]^{2}+\left[\left(\frac{\partial w}{\partial x}\right)_{x=a}\right]^{2}\right\} d y \\
& +\frac{1}{2} \int_{0}^{a} c\left\{\left[\left(\frac{\partial w}{\partial y}\right)_{y=0}\right]^{2}+\left[\left(\frac{\partial w}{\partial y}\right)_{y=b}\right]^{2}\right\} d x .
\end{aligned}
$$

By substituting $w$ from Eq. (33) and considering $c$ as constant, we get:

$$
U_{R}=\sum_{m=1}^{M} \sum_{n=1}^{N} c w_{m, n}^{2}\left[\frac{m^{2} \pi^{2} b}{2 a^{2}}+\frac{n^{2} \pi^{2} a}{2 b^{2}}\right] .
$$

For both boundary conditions, through the substitution of double Fourier series of displacement components in Eqs. (3), (21), and (23), the kinetic energy, the strain energy, and the virtual work performed by external loads will be obtained with regard to the generalized coordinates $\left(u_{m, n}, v_{m, n}\right.$, and $\left.w_{m, n}\right)$, which are suitable forms for them to use in Lagrange equations of motion. After the substitution of displacement components, the kinetic energy for both boundary conditions is obtained as follows: 


$$
T=\frac{1}{2} \rho h \frac{a b}{4} \sum_{m=1}^{M} \sum_{n=1}^{N}\left[\dot{u}_{m, n}^{2}+\dot{v}_{m, n}^{2}+\dot{w}_{m, n}^{2}\right] .
$$

Moreover, the strain energy for each of the boundary conditions is obtained as follows:

\section{Model A. Simply supported conditions}

$$
\begin{aligned}
U= & \sum_{m=1}^{M} \sum_{n=1}^{N}\left[\alpha_{1} u_{m, n}^{2}+\alpha_{2} v_{m, n}^{2}+\alpha_{3} w_{m, n}^{2}\right. \\
& \left.+\alpha_{4} u_{m, n} v_{m, n}+\alpha_{5} u_{m, n} w_{m, n}+\alpha_{6} v_{m, n} w_{m, n}\right] \\
& +\sum_{m=1}^{M} \sum_{n_{a}=n_{b}=1}^{N}\left[\alpha_{7} w_{m, n a} w_{m, n b}+\alpha_{8} u_{m, n a} w_{m, n b}\right. \\
& \left.+\alpha_{9} v_{m, n a} w_{m, n b}\right]+\sum_{m i, m j=1}^{M} \sum_{n=1}^{N}\left[\alpha_{10} w_{m i, n} w_{m j, n}\right. \\
& \left.+\alpha_{11} v_{m i, n} w_{m j, n}+\alpha_{12} u_{m i, n} w_{m j, n}\right] \\
& +\sum_{m_{i}=m_{j}=1}^{M} \sum_{n_{a}=n_{b}=1}^{N}\left[\alpha_{13} w_{m i, n a} w_{m j, n b}\right. \\
& \left.+\alpha_{14} u_{m i, n a} w_{m j, n b}+\alpha_{15} v_{m i, n a} w_{m j, n b}\right] .
\end{aligned}
$$

\section{Model B. Clamped edge conditions}

$$
\begin{aligned}
U= & \sum_{m=1}^{M} \sum_{n=1}^{N}\left[\alpha_{1} u_{m, n}^{2}+\alpha_{2} v_{m, n}^{2}+\alpha_{3} w_{m, n}^{2}\right] \\
& +\sum_{m=1}^{M} \sum_{n a, n b=1}^{N}\left[\alpha_{7} w_{m, n a} w_{m, n b}+\alpha_{16} v_{m, n a} w_{m, n b}\right] \\
& +\sum_{m i, m j=1}^{M} \sum_{n=1}^{N}\left[\alpha_{10} w_{m i, n} w_{m j, n}+\alpha_{17} u_{m i, n} w_{m j, n}\right] \\
& +\sum_{m_{i}=m_{j}=1 n_{a}=n_{b}=1}^{M}\left[\alpha_{13} w_{m i, n a} w_{m j, n b}\right. \\
& +\alpha_{18} u_{m i, n a} v_{m j, n b}+\alpha_{19} u_{m i, n a} w_{m j, n b} \\
& \left.+\alpha_{20} v_{m i, n a} w_{m j, n b}\right]+U_{R} .
\end{aligned}
$$

Basically, $U_{R}$ is the additional potential energy that is generated in the rotational springs. The coefficients $\alpha_{1}$ to $\alpha_{20}$ are presented in the appendix.

For both boundary conditions, $W$ is:

$$
\begin{aligned}
W= & \sum_{m=1}^{M} \sum_{n=1}^{N} q_{z} w_{m, n}(t) \frac{a b}{m n \pi^{2}}[\cos (0.4 m \pi) \\
& -\cos (0.6 m \pi)][\cos (0.4 n \pi)-\cos (0.6 n \pi)] .
\end{aligned}
$$

\section{Lagrange equations of motion}

The Lagrange equations of motion are:

$$
\frac{d}{d t}\left(\frac{\partial T}{\partial \dot{q}_{j}}\right)-\frac{\partial T}{\partial q_{j}}+\frac{\partial U}{\partial q_{j}}=Q_{j}, \quad j=1, \cdots, \text { dofs } s
$$

where $\mathbf{q}=\left\{u_{m, n}, v_{m, n}, w_{m, n}\right\}^{T}, m=1, \cdots, M$, $n=1, \cdots, N$, and $\operatorname{dof} s=M \times, N$. Moreover, the generalized forces $Q_{j}$ are presented in the following equation by assuming viscous type for the nonconservative damping forces:

$$
Q_{j}=-\frac{\partial F}{\partial \dot{q}_{j}}+\frac{\partial W}{\partial q_{j}} .
$$

Nonconservative damping forces of viscous type are presented as follows:

$$
\begin{aligned}
F & =\frac{1}{2} c \int_{0}^{a} \int_{0}^{b}\left(\dot{u}^{2}+\dot{v}^{2}+\dot{w}^{2}\right) d x d y \\
& =\frac{1}{2} \frac{a b}{4} \sum_{m=1}^{M} \sum_{n=1}^{N} c_{m, n}\left(\dot{u}_{m, n}^{2}+\dot{v}_{m, n}^{2}+\dot{w}_{m, n}^{2}\right), \\
\xi_{m, n} & =\frac{c_{m, n}}{\left(2 \mu_{m, n} \omega_{m, n}\right)},
\end{aligned}
$$

where $\xi_{m, n}, \mu_{m, n}$, and $\omega_{m, n}$ are modal damping ratio, natural frequency, and modal mass of mode $(m, n)$. Damping forces have insignificant effect on the responses of impact load; therefore, one can neglect damping forces.

For both boundary conditions, the kinetic energy was determined through Eq. (36). In addition, the virtual work completed by external forces was determined through Eq. (39). Therefore, three terms of the Lagrange equations are the same for both boundary conditions. In particular:

$$
\begin{aligned}
& \frac{d}{d t}\left(\frac{\partial T}{\partial \dot{q}_{j}}\right)=\rho h \frac{a b}{4} \ddot{q}_{j}, \\
& \frac{\partial T}{\partial q_{j}}=0 \\
& Q_{j}=-\frac{\partial F}{\partial \dot{q}_{j}}+\frac{\partial W}{\partial q_{j}}=-\left(\frac{a b}{4}\right) c_{j} \dot{q}_{j} \\
& \quad+\left\{\begin{array}{c}
0 \quad \text { if } q_{j}=u_{m, n}, v_{m, n} \\
q_{z} \frac{a b}{m n \pi^{2}}[\cos (0.4 m \pi)-\cos (0.6 m \pi)] \\
{[\cos (0.4 n \pi)-\cos (0.6 n \pi)]}
\end{array}\right. \\
& \text { if } q_{j}=w_{m, n}
\end{aligned}
$$


The strain energy was determined through Eqs. (37) and (38) for simply supported and clamped edge conditions, respectively. Therefore, one can write the following for each boundary condition:

$$
\frac{\partial U}{\partial q_{j}}=\sum_{k=1}^{d o f s} q_{k} \hat{\alpha}_{j, k},
$$

where coefficients $\hat{\alpha}_{j, k}$ can be determined with regard to coefficients $\alpha_{1}$ to $\alpha_{20}$.

\section{Results and discussion of numerical analysis}

The equations of motion that are obtained through the Lagrangian approach and regardless of damping forces can be presented in the following matrix form:

$$
[m][\ddot{q}]+[k][q]=[F],
$$

and:

$$
[q]=\left[q_{1} \cdots q_{j} \cdots q_{M, N}\right]^{T} .
$$

The system presented above for differential equations can be solved by the modal technique. In Eq. (48), $[\mathrm{m}]$ and $[k]$ can be considered as mass and stiffness matrices, respectively. Thus, with these two matrices, one can determine natural frequencies of the funicular shell. By solving this system of differential equations, generalized coordinates $u_{m, n}, v_{m, n}$, and $w_{m, n}$ are obtained in terms of time. Then, by using Fourier series, displacement components are determined. By determining displacement components, strains and stresses generated in the shell are acquired. In order to obtain the numerical results, a computer code was written. Furthermore, as mentioned earlier, no study is available for the dynamic response of funicular shells. Therefore, the dynamic analysis of funicular shells is completed FEM in order to compare its results with those of the analytical approach. In the present study, geometric and material properties of the funicular shell are given as follows (material is concrete):

$$
\begin{array}{ll}
a=1 \mathrm{~m}, \quad b=1 \mathrm{~m}, & E=17.8 \mathrm{GPa}, \\
\nu=0.2, \quad \rho=2400 \mathrm{~kg} / \mathrm{m}, & h=0.03 \mathrm{~m}, \\
H=0.09 \mathrm{~m} . &
\end{array}
$$

The magnitude of force $\left(F_{0}\right)$ is equal to $60 \mathrm{kPa}$, the area of applied load is $0.2 \times 0.2=0.04 \mathrm{~m}^{2}$, and the time duration of the applied load is $0.01 \mathrm{sec}$. In addition, the number of considered degrees of freedom used in the mode expansion of displacement components $(m, n)$ is $(3 \times 15)$ for simply supported conditions and $(4 \times 15)$ for clamped edge conditions. Moreover, there are 10 considered modes in the modal analysis technique for both methods, i.e., analytical and FEM.

\begin{tabular}{|c|c|c|}
\hline \multirow[t]{2}{*}{ Boundary conditions } & \multicolumn{2}{|c|}{$\begin{array}{c}\text { Natural frequency } \\
(\mathrm{Hz})\end{array}$} \\
\hline & Analytical & FEM \\
\hline Simply supported & 197.77 & 195.57 \\
\hline Clamped $\quad c=0$ & 362.84 & 380.39 \\
\hline$c=180000(\mathrm{~N} / \mathrm{rad})$ & 379.85 & 380.39 \\
\hline
\end{tabular}
Evidently, Figure 3 indicates the comparison of the

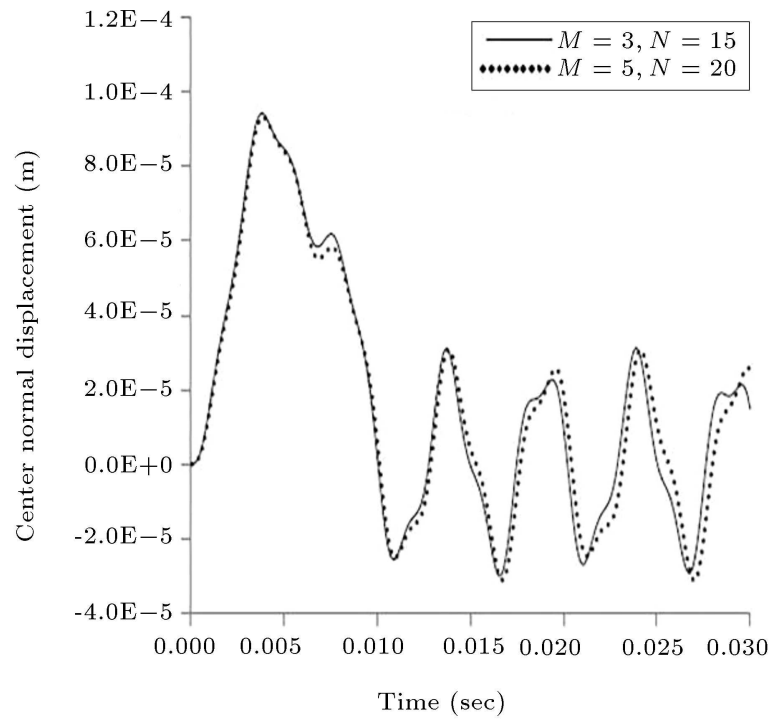

Figure 3. Comparison of center normal displacement of simply supported conditions for two different cases.

Table 1. Natural frequency of mode $(1,1)$ for different boundary conditions.

center deflection of a simply supported funicular shell for two different cases. In case 1, the number of degrees of freedom used in the mode expansion is $(3 \times 15)$ and in case 2 is $(5 \times 20)$. The good agreement between the results shown in Figure 3 shows the convergence of Fourier series of displacement components.

Table 1 shows the natural frequency of mode $(1,1)$ that is obtained with analytical and FEMs for each of the two different boundary conditions. The agreement between the analytical solution and FEM solution is excellent, as is clearly shown in Table 1. For clamped edge conditions, good agreement is obtained for $c=$ 180000. All of the results of the analytical method pertaining to clamped edge conditions that are presented subsequently are obtained for $c=180000 \mathrm{~N} / \mathrm{rad}$.

Tables 2 and 3 present a comparison of the maximum values of center normal deflection along with the center stresses found in $x$ direction with FEM for different impulse loads.

Figure 4 shows the center normal displacement of simply supported in comparison with the FEM. Figure 5 also shows this comparison for clamped edge conditions.

The good agreement between the results found in Tables 2 and 3 along with Figures 4 and 5 indicates 
Table 2. Comparison of the maximum values of center normal deflection and center stresses of simply supported conditions for different pulses.

\begin{tabular}{ccccc}
\hline \multirow{2}{*}{ Impulse load } & $\begin{array}{c}\text { Deflection } \\
\left(\times \mathbf{1 0}^{-4} \mathbf{~ m}\right)\end{array}$ & \multicolumn{2}{c}{$\boldsymbol{\sigma}_{\boldsymbol{x}}(\mathbf{M P a})$} \\
\cline { 4 - 5 } Step pulse & Analytical & 1.6 & -1.9 & 0.66 \\
& FEM & 1.6 & -1.7 & 0.84 \\
\multirow{2}{*}{$\begin{array}{c}\text { Triangular } \\
\text { pulse }\end{array}$} & Analytical & 1.3 & -1.6 & 1 \\
& FEM & 1.3 & -1.4 & 0.87 \\
Sine pulse & Analytical & 0.94 & -1.1 & 0.24 \\
& FEM & 0.95 & -0.92 & 0.19 \\
\hline
\end{tabular}

*: Compression; **: Tension.

Table 3. Comparison of the maximum values of center normal deflection and center stresses of clamped edge for different pulses.

\begin{tabular}{ccccc}
\hline \multirow{2}{*}{ Impulse load } & $\begin{array}{c}\text { Deflection } \\
\left(\times \mathbf{1 0}^{-4} \mathbf{m}\right)\end{array}$ & \multicolumn{2}{c}{$\mathbf{C}_{\boldsymbol{x}}(\mathbf{M P a})$} \\
\hline \multirow{2}{*}{ Step pulse } & Analytical & 0.92 & -1.6 & $\mathbf{T}^{* *}$ \\
& FEM & 1 & -1.8 & 0.87 \\
& & & & \\
Triangular & Analytical & 0.83 & -1.5 & 0.83 \\
pulse & FEM & 0.88 & -1.6 & 0.95 \\
& & & & \\
Sine pulse & Analytical & 0.51 & -0.89 & 0.19 \\
& FEM & 0.59 & -1 & 0.2 \\
\hline
\end{tabular}

*: Compression; **: Tension.

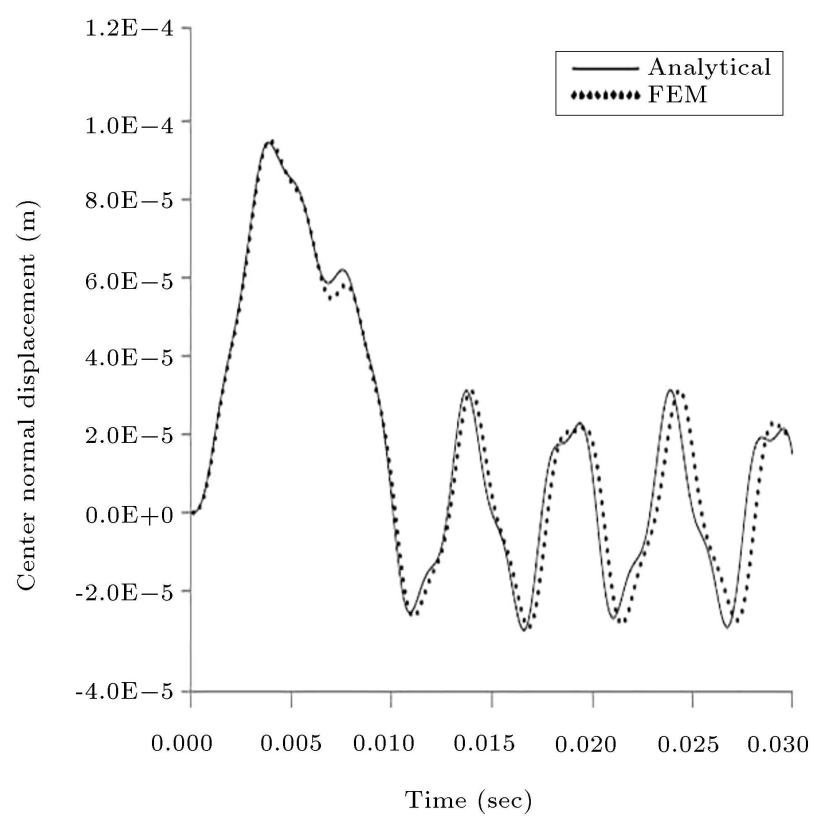

Figure 4. Center normal displacement of simply supported conditions for sine pulse.

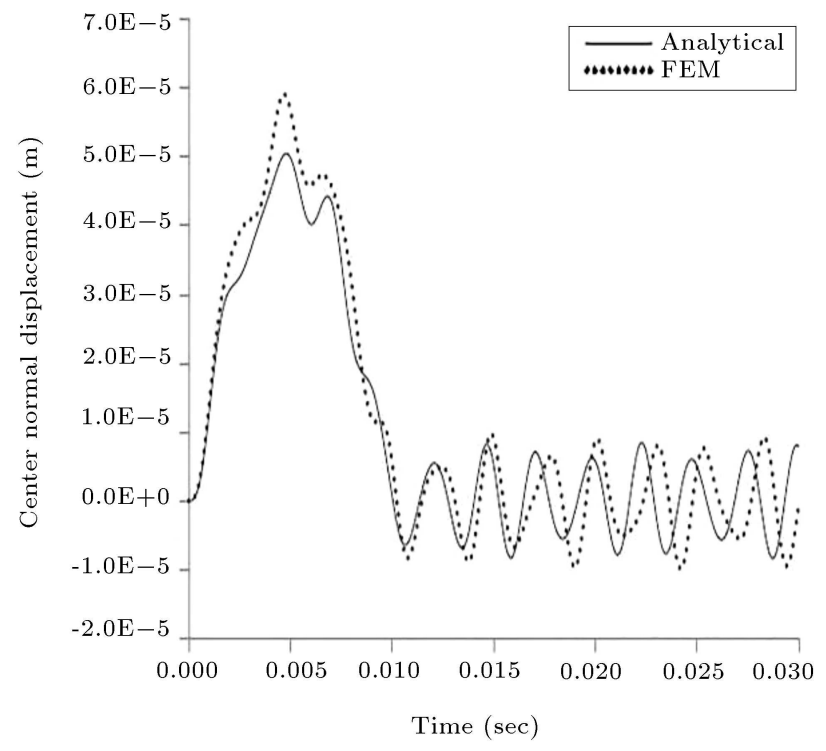

Figure 5. Center normal displacement of clamped edge conditions for sine pulse.

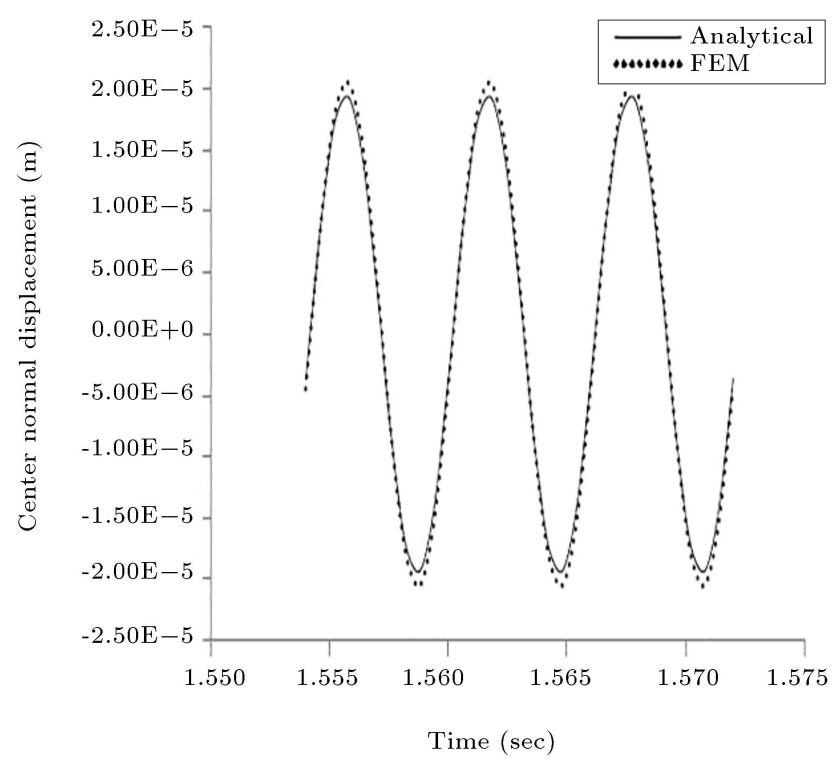

Figure 6. Center normal displacement of simply supported conditions for harmonic load.

the validity of the proposed method. In Figure 5, the comparison of the proposed method and finite element shows a phase difference between the results that could be related to the value of the stiffness $c$ (stiffness of rotational springs). In order to simulate clamped edges, the value of the stiffness $c$ is determined only with regard to the natural frequency of mode $(1,1)$.

Figure 6 shows the comparison of center deflection of simply supported and the FEM for a harmonic force, $q_{z}=F_{0} \sin (\omega t)$, where the load frequency $(\omega)$ is equal to $1.2 \omega_{1,1}\left(\omega_{1,1}\right.$ is the natural frequency of the fundamental mode). In regard to the harmonic load, the effect of damping should be considered. The 


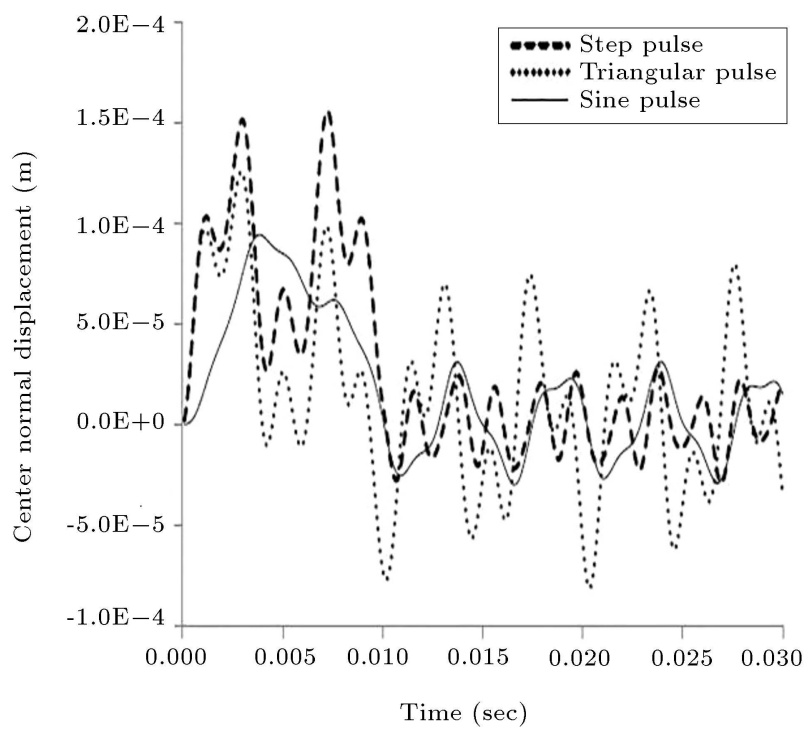

Figure 7. Center normal displacement of simply supported conditions for different pulses.

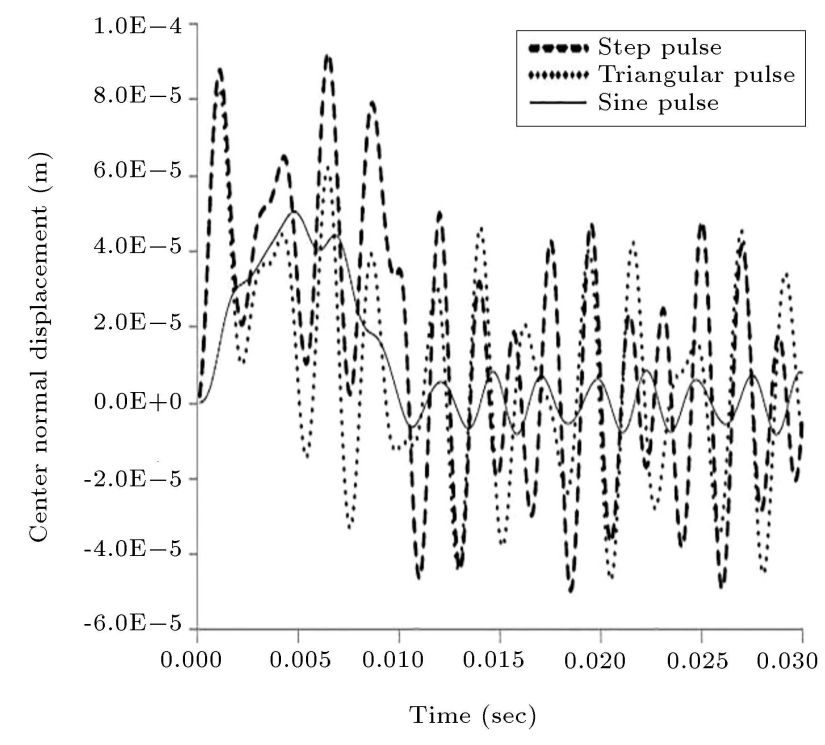

Figure 8. Center normal displacement of clamped edge conditions for different pulses.

modal damping ratio of all modes is to be assumed $4 \%$, and the magnitude of force $\left(F_{0}\right)$ is equal to $6 \mathrm{kPa}$. Figure 6 shows good convergence between the results of two methods for harmonic load.

Figures 7 and 8 show the time response of the center point displacement of the funicular shell with various pulses for simply supported and clamped edge conditions, respectively. The largest deflection occurs under step pulse due to the area under the load-time curve being greater than other pulses.

Tables 4 and 5 indicate the maximum and minimum values of internal forces and moments for simply supported and clamped edge conditions, respectively.

Tables 6 and 7 also indicate the maximum values
Table 4. The maximum and minimum values of internal forces and moments of simply supported conditions for different pulses.

\begin{tabular}{ccccc}
\hline \multicolumn{2}{c}{$\begin{array}{c}\text { Internal forces } \\
\text { and moments }\end{array}$} & $\begin{array}{c}\text { Step } \\
\text { pulse }\end{array}$ & $\begin{array}{c}\text { Triangular } \\
\text { pulse }\end{array}$ & $\begin{array}{c}\text { Sine } \\
\text { pulse }\end{array}$ \\
\hline \multirow{2}{*}{$N_{x}(\mathrm{kN} / \mathrm{m})$} & Max & 5.45 & 11.8 & 3.73 \\
& Min & -23.1 & -19.2 & -13.5 \\
& & & & \\
$N_{y}(\mathrm{kN} / \mathrm{m})$ & Max & 5.99 & 12.5 & 3.71 \\
& Min & -23.9 & -19.5 & -13.5 \\
& & & & \\
$N_{x y}(\mathrm{kN} / \mathrm{m})$ & Max & 9.52 & 18.3 & 8.82 \\
& Min & -31.6 & -28.7 & -20 \\
& & & & \\
$M_{x}(\mathrm{~N} . \mathrm{M} / \mathrm{M})$ & Max & 176 & 160 & 97.1 \\
& Min & -122 & -105 & -43.4 \\
& & & & \\
$M_{y}(\mathrm{~N} . \mathrm{M} / \mathrm{M})$ & Max & 164 & 155 & 93.5 \\
& Min & -116 & -102 & -43 \\
& & & & \\
$M_{x y}(\mathrm{~N} . \mathrm{M} / \mathrm{M})$ & Max & 34.9 & 77.5 & 31.5 \\
& Min & -115 & -108 & -55.6 \\
\hline
\end{tabular}

Table 5. The maximum and minimum values of internal forces and moments of clamped edge for different pulses.

\begin{tabular}{ccccc}
\hline \multicolumn{2}{c}{$\begin{array}{c}\text { Internal forces } \\
\text { and moments }\end{array}$} & $\begin{array}{c}\text { Step } \\
\text { pulse }\end{array}$ & $\begin{array}{c}\text { Triangular } \\
\text { pulse }\end{array}$ & $\begin{array}{c}\text { Sine } \\
\text { pulse }\end{array}$ \\
\hline \multirow{2}{*}{$N_{x}(\mathrm{kN} / \mathrm{m})$} & Max & 8.9 & 9.92 & 1.94 \\
& Min & -19.3 & -17.8 & -10.8 \\
& & & & \\
$N_{y}(\mathrm{kN} / \mathrm{m})$ & Max & 10.8 & 10.8 & 2.09 \\
& Min & -21.4 & -18.9 & -11.6 \\
& & & & \\
$N_{x y}(\mathrm{kN} / \mathrm{m})$ & Max & 8.31 & 7.72 & 1.37 \\
& Min & -12.6 & -11.5 & -7.03 \\
& & & & \\
$M_{x}(\mathrm{~N} . \mathrm{M} / \mathrm{M})$ & Max & 151 & 135 & 80.9 \\
& Min & -108 & -75 & -44.1 \\
& & & & \\
$M_{y}(\mathrm{~N} . \mathrm{M} / \mathrm{M})$ & Max & 141 & 131 & 78 \\
& Min & -101 & -79.4 & -46.4 \\
& & & & \\
$M_{x y}(\mathrm{~N} . \mathrm{M} / \mathrm{M})$ & Max & 30.4 & 26.1 & 9.32 \\
& Min & -40.7 & -37.2 & -22.2 \\
\hline
\end{tabular}

of compressive, tensile, and shear stresses found in the funicular shell for two boundary conditions.

Tables 4 to 7 show that, under impulse loads, internal moments form and, thus, tensile and shear stresses in addition to compressive stresses form. In this paper, for a plate with the same geometric and material features and for the same load applied, the dy- 
Table 6. The maximum values of stresses of simply supported conditions for different pulses.

\begin{tabular}{|c|c|c|c|c|}
\hline \multicolumn{2}{|c|}{ Stresses } & \multirow{2}{*}{$\begin{array}{c}\begin{array}{c}\text { Step } \\
\text { pulse }\end{array} \\
0.69\end{array}$} & \multirow{2}{*}{$\begin{array}{c}\begin{array}{c}\text { Triangular } \\
\text { pulse }\end{array} \\
1.02\end{array}$} & \multirow{2}{*}{$\begin{array}{c}\begin{array}{c}\text { Sine } \\
\text { pulse }\end{array} \\
0.267\end{array}$} \\
\hline$\sigma_{x}$ & Tension & & & \\
\hline$(\mathrm{MPa})$ & Compression & -1.94 & -1.61 & -1.06 \\
\hline \multirow{2}{*}{$\begin{array}{c}\sigma_{y} \\
(\mathrm{MPa})\end{array}$} & Tension & 0.674 & 0.968 & 0.312 \\
\hline & Compression & -1.88 & -1.6 & -1.04 \\
\hline$\tau_{x y}(\mathrm{MPa})$ & & 1.38 & 1.16 & 0.866 \\
\hline
\end{tabular}

Table 7. The maximum values of stresses of clamped edge for different pulses.

\begin{tabular}{crccc}
\hline \multirow{2}{*}{ Stresses } & $\begin{array}{c}\text { Step } \\
\text { pulse }\end{array}$ & $\begin{array}{c}\text { Triangular } \\
\text { pulse }\end{array}$ & $\begin{array}{c}\text { Sine } \\
\text { pulse }\end{array}$ \\
\hline $\begin{array}{c}\sigma_{x} \\
(\mathrm{MPa})\end{array}$ & Tension & 1.01 & 0.828 & 0.193 \\
& Compression & -1.65 & -1.48 & -0.895 \\
& & & & \\
$\sigma_{y}$ & Tension & 1.03 & 0.831 & 0.151 \\
$(\mathrm{MPa})$ & Compression & -1.65 & -1.5 & -0.902 \\
& & & & \\
$\tau_{x y}(\mathrm{MPa})$ & & 0.613 & 0.556 & 0.338 \\
\hline
\end{tabular}

Table 8. Comparison of the maximum values of center normal deflection and center stresses of simply supported conditions.

\begin{tabular}{lcccc}
\hline \multirow{2}{*}{ Impulse load } & $\begin{array}{c}\text { Deflection } \\
\left(\times \mathbf{1 0}^{-4} \mathbf{~ m}\right)\end{array}$ & \multicolumn{2}{c}{$\boldsymbol{\sigma}_{\boldsymbol{x}}(\mathbf{M P a})$} \\
\hline \multirow{2}{*}{ Step } & Funicular shell & 1.56 & -1.67 & 0.842 \\
pulse & Plate & 12.2 & -4.6 & 4.6 \\
& & & & \\
Sine & Funicular shell & 0.948 & -0.924 & 0.192 \\
pulse & Plate & 10.3 & -3.64 & 3.64 \\
\hline
\end{tabular}

\footnotetext{
*: Compression; **: Tension.
}

namic responses are obtained with the FEM. Tables 8 and 9 show the comparison of the maximum values of center normal deflection, center compressive, and tensile stresses between the funicular shell and the plate for simply supported and clamped edge conditions, respectively.

Tables 8 and 9 indicate that, in regard to the plate, the compressive and tensile stresses are the same due to the bending performance of the plate. The tables also indicate that the normal deflection and
Table 9. Comparison of the maximum values of center normal deflection and center stresses of clamped edge conditions.

\begin{tabular}{lcccc}
\hline \multirow{2}{*}{ Impulse load } & $\begin{array}{c}\text { Deflection } \\
\left(\times \mathbf{1 0}^{-4} \mathbf{~ m}\right)\end{array}$ & \multicolumn{2}{c}{$\mathbf{C}_{\boldsymbol{x}}(\mathbf{M P a})$} & $\mathbf{T}^{* *}$ \\
\hline \multirow{2}{*}{$\begin{array}{c}\text { Step } \\
\text { pulse }\end{array}$} & Funicular shell & 1.04 & -1.83 & 0.871 \\
& Plate & 5.33 & -3.49 & 3.49 \\
& & & & \\
Sine & Funicular shell & 0.591 & -1.03 & 0.195 \\
pulse & Plate & & & \\
\hline
\end{tabular}

*: Compression; **: Tension.

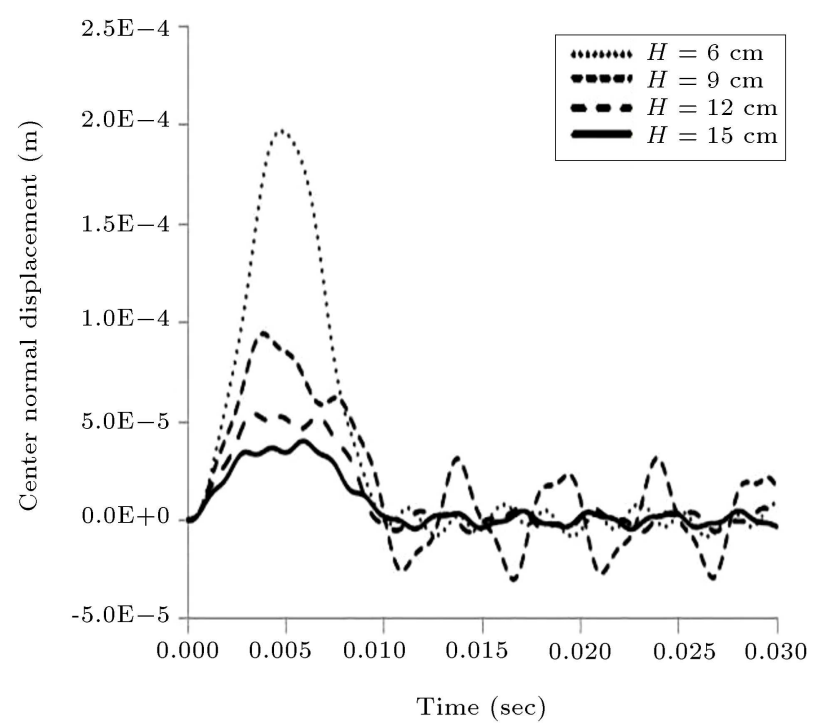

Figure 9. Center normal displacement of simply supported conditions for sine pulse and also for different rises.

stresses, especially tensile stresses found in the plate, are larger than those of funicular shell. In other words, tensile stresses found in the plate are 4 to 15 times larger than those found in the funicular shell.

Essentially, as mentioned in the introduction, the rise of the funicular shell is an important parameter in the performance of the funicular shell under static loads. Here, the effect of the rise of the funicular shell is considered for dynamic load. By increasing the rise of the shell, the maximum value of center normal displacement and the corresponding time response will decrease (Figure 9).

If the dimension of plan $(a)$ increases, the maximum values of center normal displacement and stresses along with time response of normal displacement will increase (Table 10 and Figure 10).

Table 10 indicates that, for $a=3 \mathrm{~m}$, the center tensile stress of the funicular shell is $9.8 \mathrm{MPa}$. By increasing the shell rise from $H=0.15 \mathrm{~m}$ to $H=$ 
Table 10. Comparison of the maximum value of center stresses of simply supported conditions for sine pulse and also for different plan dimensions.

\begin{tabular}{ccc}
\hline \multirow{2}{*}{$\begin{array}{c}\text { Plan } \\
\text { dimension }(a)\end{array}$} & \multicolumn{2}{c}{$\boldsymbol{\sigma}_{\boldsymbol{x}}(\mathrm{MPa})$} \\
\cline { 2 - 3 } & Compression & Tension \\
\hline 1.5 & -1.72 & 0.495 \\
2 & -3.71 & 0.617 \\
2.5 & -6.92 & 5.16 \\
3 & -10.2 & 9.8 \\
\hline
\end{tabular}

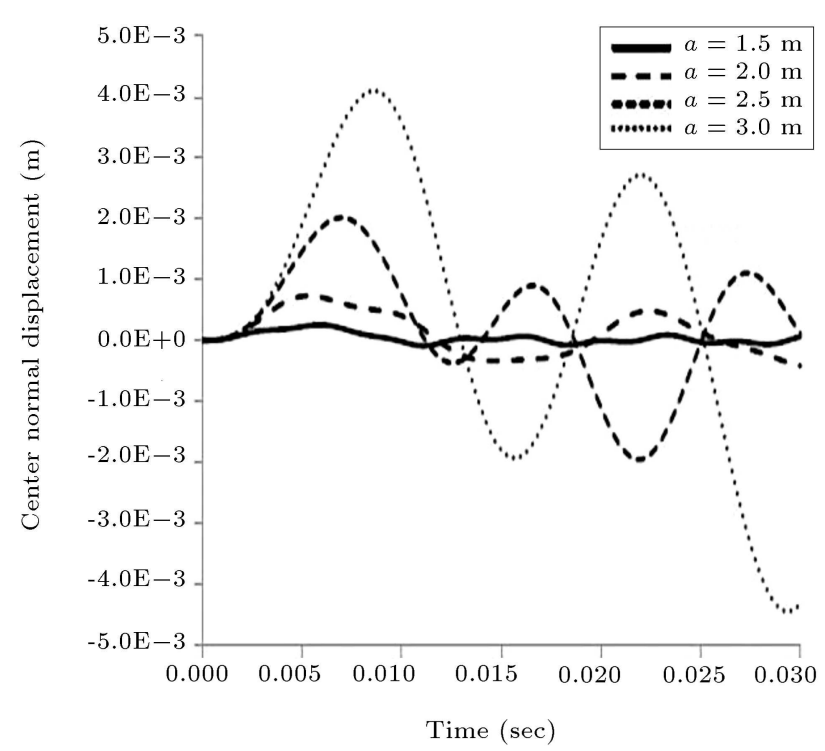

Figure 10. Center normal displacement of simply supported conditions for sine pulse and also for different plan dimensions.

$0.27 \mathrm{~m}$, the center tensile stress of the shell decreases to $3.3 \mathrm{MPa}$, which shows a $67 \%$ reduction. Thus, the span-to-rise ratio significantly affects the stresses, particularly tensile stresses.

\section{Summary and conclusions}

In this study, an analytical solution in regard to the forced linear vibration of concrete funicular shells on a rectangular ground plan under impulse loads for two different boundary conditions was presented based on the shallow shells theory. The results, successfully verified against finite element technique, reveal that:

- The largest deflection occurs under step pulse due to the area under time-load curve being greater than the other two pulses;

- The performance of the funicular shell under impulse loads is much better than that of the rectangular flat plate;
- Under impulse loads, tensile stresses in addition to compressive stresses form in funicular shells;

- The deflections and stresses, especially tensile stresses, under dynamic impulse loads are negligible up to an amplitude of the load that is computable;

- The effect of rise and span on the time response of the shell has been considered. From a general perspective, the smaller the ratio of span to rise is, the smaller the displacements and stresses will be. In fact, by choosing an appropriate span-torise ratio, the displacements and stresses, especially tensile stresses, will decrease significantly.

\section{References}

1. Bhimaraddi, A. "Free vibration analysis of doubly curved shallow shells on rectangular planform using three-dimensional elasticity theory", Int. J. Solids Struct., 27(7), pp. 897-913 (1991).

2. Singh, V.K. and Panda, S.K. "Nonlinear free vibration analysis of single/doubly curved composite shallow shell panels", Thin Walled Struct., 85, pp. 341-349 (2014).

3. Qatu, M.S. and Leissa, A.W. "Effects of edge constraint upon shallow shell frequencies", Thin Walled Struct., 14(5), pp. 347-379 (1992).

4. Abe, A., Kobayashi, Y., and Yamada, G. "Non-linear vibration characteristics of clamped laminated shallow shells", J. Sound Vib., 234(3), pp. 405-426 (2000).

5. Amabili, M. "Non-linear vibrations of doubly curved shallow shells", Int. J. Non Linear Mech., 40, pp. 683710 (2005).

6. Shoshtari, A. and Razavi, S. "Large-amplitude free vibration of magneto-electro-static curved panels", Scientia Iranica, 23(6), pp. 2606-2615 (2016).

7. Vafai, A., Mofid, M., and Estekanchi, H.E. "Experimental study of prefabricated funicular shell units", Eng. Struct., 19(9), pp. 748-759 (1997).

8. Weber, J.W., Wu, K.C., and Vafai, A. "Ultimate loads for shallow funicular concrete shells", Northwest Sci., 58(3), pp. 187-194 (1984).

9. Vafai, A. and Farshad, M. "Theoretical and experimental study of prefabricated funicular shell units", Build. Environ., 14, pp. 209-216 (1979).

10. Elangovan, S. "Analysis of funicular shells by the isoparametric finite element", Comput. Struct., 34(2), pp. 303-311 (1990).

11. Rajasekaran, S. and Sujatha, P. "Configuration of deep funicular shells by boundary integral element method", Comput. Struct., 44(1/2), pp. 213-221 (1992).

12. Lakshmikandhan, K.N., Sivakumar, P., Jose, L.T., Sivasubramanian, K., Balasubramanian, S.R., and Saibabu, S. "Parametric study on development, testing 
and evaluation of concrete funicular shells", International Journal of Engineering and Innovative Technology (IJEIT), 3(12), pp. 183-191 (2014).

13. Sivakumar, P., Manjunatha, K., and Harish, B.A. "Experimental and FE analysis of funicular shells", International Journal of Engineering and Innovative Technology (IJEIT), 4(9), pp. 178-186 (2015).

14. Siddesh, T.M., Harish, B.A., and Manjunatha, K. "Finite element analysis of funicular shells with rectangular plan ratio 1:0.7 under concentrated load using SAP2000", International Research Journal of Engineering and Technology (IRJET), 3(9), pp. 873-878 (2016).

15. Sachithanantham, P. "Study of shallow funicular concrete shells of plan to rise ratio 1:2", International Journal of Biotech Trends and Technology (IJBTT), 2(3), pp. 53-64 (2012).

16. Tarunkumar, T. and Sachithanantham, P. "Study on shallow funicular concrete shells over rectangular ground plan ratio 1:0.8", International Journal of Computer Trends and Technology (IJCTT), 3(6), pp. 29-49 (2012).

17. Sachithanantham, P. "Study of geo-grid reinforced shallow funicular concrete shells subjected to ultimate loads", International Journal of Biotech Trends and Technology (IJBTT), 2(2), pp. 34-46 (2012).

18. Sachithanantham, P., Sankaran, S., and Elavenil, S. "Study on shallow funicular concrete shells over rectangular ground plan ratio 1:0.6", International Journal of Computer Trends and Technology (IJCTT), 3(6), pp. 19-28 (2012).

19. Sachithanantham, P., Sankaran, S., and Elavenil, S. "Study on shallow funicular concrete shells over rectangular ground plan ratio 1:0.9", International Journal of Emerging Technology and Advanced Engineering (IJETAE), 4(4), pp. 102-107 (2014).

20. Ramaswamy, G.S., Design and Construction of Concrete Shell Roofs, McGraw-Hill, New York, USA (1968).

21. Ventsel, E. and Krauthammer, T., Thin Plates and Shells, Theory, Analysis, and Applications, Marcel Dekker, New York, USA (2001).

22. Amabili, M. "Effect of boundary conditions on nonlinear vibrations of circular cylindrical panels", J. Appl. Mech., 74, pp. 645-657 (2007).

\section{Appendix}

Definitions of $\alpha_{1}-\alpha_{20}$ :

$$
\begin{aligned}
& \alpha_{1}=\frac{E h}{2\left(1-\nu^{2}\right)}\left[\frac{m^{2} \pi^{2} b}{4 a}+(1-\nu) \frac{n^{2} \pi^{2} a}{8 b}\right], \\
& \alpha_{2}=\frac{E h}{2\left(1-\nu^{2}\right)}\left[\frac{n^{2} \pi^{2} a}{4 b}+(1-\nu) \frac{m^{2} \pi^{2} b}{8 a}\right],
\end{aligned}
$$

$$
\begin{aligned}
& \alpha_{3}=\frac{E h^{3}}{24\left(1-\nu^{2}\right)}\left[\frac{m^{4} \pi^{4} b}{4 a^{3}}+\frac{n^{4} \pi^{4} a}{4 b^{3}}+\frac{m^{2} n^{2} \pi^{4}}{2 a b}\right] \\
& +\frac{E h}{2\left(1-\nu^{2}\right)}\left[\frac{25 g^{2}}{2 N^{2}}\left(\frac{1}{a^{2}+b^{2}}\right)^{2}\right] \\
& \left\{a\left[\frac{b^{5}}{60}+\frac{3 b^{5}}{4 n^{4} \pi^{4}}\right]+b\left[\frac{a^{5}}{60}+\frac{3 a^{5}}{4 m^{4} \pi^{4}}\right]\right. \\
& +4 \nu\left[\frac{b^{3}}{12}+\frac{b^{3}}{4 n^{2} \pi^{2}}\right]\left[\frac{a^{3}}{12}+\frac{a^{3}}{4 m^{2} \pi^{2}}\right] \\
& \left.+(1-\nu)\left[\frac{a^{3}}{6}-\frac{a^{3}}{m^{2} \pi^{2}}\right]\left[\frac{b^{3}}{6}-\frac{b^{3}}{n^{2} \pi^{2}}\right]\right\}, \\
& \alpha_{4}=\frac{E h}{2\left(1-\nu^{2}\right)}\left[(1+\nu) \frac{m n \pi^{2}}{4}\right] \text {, } \\
& \alpha_{5}=\frac{E h}{2\left(1-\nu^{2}\right)}\left[5 \frac{g}{N} \frac{1}{\left(a^{2}+b^{2}\right)}\right]\left\{-m \pi\left[\frac{b^{3}}{12}+\frac{b^{3}}{4 n^{2} \pi^{2}}\right]\right. \\
& \left.-\nu \frac{m \pi b}{a}\left[\frac{a^{3}}{12}+\frac{a^{3}}{4 m^{2} \pi^{2}}\right]-(1-\nu) \frac{a^{2} b}{4 m \pi}\right\}, \\
& \alpha_{6}=\frac{E h}{2\left(1-\nu^{2}\right)}\left[5 \frac{g}{N} \frac{1}{\left(a^{2}+b^{2}\right)}\right]\left\{-n \pi\left[\frac{a^{3}}{12}+\frac{a^{3}}{4 m^{2} \pi^{2}}\right]\right. \\
& \left.-\nu \frac{n \pi a}{b}\left[\frac{b^{3}}{12}+\frac{b^{3}}{4 n^{2} \pi^{2}}\right]-(1-\nu) \frac{b^{2} a}{4 n \pi}\right\}, \\
& \alpha_{7}=\frac{E h}{2\left(1-\nu^{2}\right)}\left[-25\left[\frac{g}{N} \frac{1}{\left(a^{2}+b^{2}\right)}\right]^{2}\right] \\
& \left\{\frac{16 \nu b^{3} n_{a} n_{b}}{\pi^{2}\left(n_{a}^{2}-n_{b}^{2}\right)^{2}}\left[\frac{a^{3}}{12}+\frac{a^{3}}{4 m^{2} \pi^{2}}\right]\right. \\
& +\frac{96 a b^{5} n_{a} n_{b}\left(n_{a}^{2}+n_{b}^{2}\right)}{\pi^{4}\left(n_{a}^{2}-n_{b}^{2}\right)^{4}} \\
& \left.-(1-\nu) \frac{16 b^{3} n_{a} n_{b}}{\pi^{2}\left(n_{a}^{2}-n_{b}^{2}\right)^{2}}\left[\frac{a^{3}}{6}-\frac{a^{3}}{m^{2} \pi^{2}}\right]\right\}, \\
& \alpha_{8}=\frac{E h}{2\left(1-\nu^{2}\right)}\left[\frac{g}{N} \frac{1}{\left(a^{2}+b^{2}\right)}\right]\left[\frac{20 m b^{3} n_{a} n_{b}}{\pi\left(n_{a}^{2}-n_{b}^{2}\right)^{2}}\right. \\
& \left.+\frac{5(1-\nu) a^{2} b n_{a} n_{b}}{m \pi\left(n_{a}^{2}-n_{b}^{2}\right)}\right] \\
& \alpha_{9}=\frac{E h}{2\left(1-\nu^{2}\right)}\left[\frac{g}{N} \frac{1}{\left(a^{2}+b^{2}\right)}\right]\left[\frac{20 \nu a b^{2} n_{a}^{2} n_{b}}{\pi\left(n_{a}^{2}-n_{b}^{2}\right)^{2}}\right. \\
& \left.+\frac{5(1-\nu) a b^{2} n_{b}}{\pi\left(n_{a}^{2}-n_{b}^{2}\right)}\right] \text {, }
\end{aligned}
$$




$$
\begin{aligned}
& \alpha_{10}=\frac{E h}{2\left(1-\nu^{2}\right)}\left[-25\left[\frac{g}{N} \frac{1}{\left(a^{2}+b^{2}\right)}\right]^{2}\right] \\
& \left\{\frac{16 \nu a^{3} m_{i} m_{j}}{\pi^{2}\left(m_{i}^{2}-m_{j}^{2}\right)^{2}}\left[\frac{b^{3}}{12}+\frac{b^{3}}{4 n^{2} \pi^{2}}\right]\right. \\
& +\frac{96 b a^{5} m_{i} m_{j}\left(m_{i}^{2}+m_{j}^{2}\right)}{\pi^{4}\left(m_{i}^{2}-m_{j}^{2}\right)^{4}} \\
& \left.-(1-\nu) \frac{16 a^{3} m_{i} m_{j}}{\pi^{2}\left(m_{i}^{2}-m_{j}^{2}\right)^{2}}\left[\frac{b^{3}}{6}-\frac{b^{3}}{n^{2} \pi^{2}}\right]\right\}, \\
& \alpha_{11}=\frac{E h}{2\left(1-\nu^{2}\right)}\left[\frac{g}{N} \frac{1}{\left(a^{2}+b^{2}\right)}\right]\left[\frac{20 n a^{3} m_{i} m_{j}}{\pi\left(m_{i}^{2}-m_{j}^{2}\right)^{2}}\right. \\
& \left.+\frac{5(1-\nu) b^{2} a m_{i} m_{j}}{n \pi\left(m_{i}^{2}-m_{j}^{2}\right)}\right] \\
& \alpha_{12}=\frac{E h}{2\left(1-\nu^{2}\right)}\left[\frac{g}{N} \frac{1}{\left(a^{2}+b^{2}\right)}\right]\left[\frac{20 \nu b a^{2} m_{i}^{2} m_{j}}{\pi\left(m_{i}^{2}-m_{j}^{2}\right)^{2}}\right. \\
& \left.+\frac{5(1-\nu) b a^{2} m_{j}}{\pi\left(m_{i}^{2}-m_{j}^{2}\right)}\right] . \\
& \alpha_{13}=\frac{E h}{2\left(1-\nu^{2}\right)}\left[\frac{g}{N} \frac{1}{\left(a^{2}+b^{2}\right)}\right]^{2} \\
& {\left[\frac{1600 \nu a^{3} b^{3} m_{i} m_{j} n_{a} n_{b}}{\pi^{4}\left(m_{i}^{2}-m_{j}^{2}\right)^{2}\left(n_{a}^{2}-n_{b}^{2}\right)^{2}}\right.} \\
& \left.+\frac{6400(1-\nu) a^{3} b^{3} m_{i} m_{j} n_{a} n_{b}}{\pi^{2}\left(m_{i}^{2}-m_{j}^{2}\right)^{2}\left(n_{a}^{2}-n_{b}^{2}\right)^{2}}\right], \\
& \alpha_{14}=\frac{E h}{2\left(1-\nu^{2}\right)}\left[\frac{g}{N} \frac{1}{\left(a^{2}+b^{2}\right)}\right]\left[\frac{20(1-\nu) a^{2} b m_{j} n_{a} n_{b}}{\pi\left(m_{i}^{2}-m_{j}^{2}\right)\left(n_{a}^{2}-n_{b}^{2}\right)}\right], \\
& \alpha_{15}=\frac{E h}{2\left(1-\nu^{2}\right)}\left[\frac{g}{N} \frac{1}{\left(a^{2}+b^{2}\right)}\right]\left[\frac{20(1-\nu) b^{2} a m_{i} m_{j} n_{b}}{\pi\left(m_{i}^{2}-m_{j}^{2}\right)\left(n_{a}^{2}-n_{b}^{2}\right)}\right] .
\end{aligned}
$$

For $\alpha_{7}-\alpha_{15}$, indices of $m(i, j)$ and indices of $n$, $(a, b)$ should be either even or odd. Otherwise, these coefficients will be zero.

$$
\begin{aligned}
& \alpha_{16}=\frac{E h}{2\left(1-\nu^{2}\right)}\left[-20 \frac{g}{N} \frac{1}{\left(a^{2}+b^{2}\right)}\right] \\
&\left\{\frac{\nu a b^{2} n_{a} n_{b}\left(3 n_{a}^{2}+n_{b}^{2}\right)}{\pi^{2}\left(n_{a}^{2}-n_{b}^{2}\right)^{3}}+\frac{n_{a} n_{b}}{\left(n_{a}^{2}-n_{b}^{2}\right)}\right. \\
& {\left.\left[\frac{a^{3}}{12}+\frac{a^{3}}{4 m^{2} \pi^{2}}\right]+(1-\nu) \frac{b^{2} a n_{a} n_{b}}{\pi^{2}\left(n_{a}^{2}-n_{b}^{2}\right)^{2}}\right\} . }
\end{aligned}
$$

In the above equation, one of the indices of $n, a$ or $b$ should be even, and the other one should be odd. Otherwise, this equation will be equal to zero.

$$
\begin{aligned}
& \alpha_{17}=\frac{E h}{2\left(1-\nu^{2}\right)}\left[-20 \frac{g}{N} \frac{1}{\left(a^{2}+b^{2}\right)}\right] \\
&\left\{\frac{\nu b a^{2} m_{i} m_{j}\left(3 m_{i}^{2}+m_{j}^{2}\right)}{\pi^{2}\left(m_{i}^{2}-m_{j}^{2}\right)^{3}}+\frac{m_{i} m_{j}}{\left(m_{i}^{2}-m_{j}^{2}\right)}\right. \\
& {\left.\left[\frac{b^{3}}{12}+\frac{b^{3}}{4 n^{2} \pi^{2}}\right]+(1-\nu) \frac{a^{2} b m_{i} m_{j}}{\pi^{2}\left(m_{i}^{2}-m_{j}^{2}\right)^{2}}\right\} . }
\end{aligned}
$$

In the above equation, one of the indices of $m, i$ or $j$ should be even, and the other one should be odd. Otherwise, this equation will be equal to zero.

$$
\alpha_{18}=\frac{E h}{2\left(1-\nu^{2}\right)}\left[-4(1+\nu) \frac{m_{i} m_{j} n_{a} n_{b}}{\left(m_{i}^{2}-m_{j}^{2}\right)\left(n_{a}^{2}-n_{b}^{2}\right)}\right] .
$$

In the above equation, one of the indices of $m, i$ or $j$ should be even, and the other one should be odd; similarly, one of the indices of $n, a$ or $b$ should be even, and the other one should be odd. Otherwise, this equation will be equal to zero.

$$
\begin{aligned}
\alpha_{19}= & \frac{E h}{2\left(1-\nu^{2}\right)}\left[80 \frac{g}{N} \frac{1}{\left(a^{2}+b^{2}\right)}\right]\left[\frac{b^{3} m_{i} m_{j} n_{a} n_{b}}{\pi^{2}\left(n_{a}^{2}-n_{b}^{2}\right)^{2}\left(m_{i}^{2}-m_{j}^{2}\right)}\right. \\
& \left.+\frac{(1-\nu) a^{2} b m_{i} m_{j} n_{a} n_{b}}{\pi^{2}\left(m_{i}^{2}-m_{j}^{2}\right)^{2}\left(n_{a}^{2}-n_{b}^{2}\right)}\right] .
\end{aligned}
$$

In the above equation, one of the indices of $m, i$ or $j$ should be even, the other one should be odd, and both indices of $n, a$ and $b$ should be even or odd. Otherwise, this equation will be equal to zero.

$$
\begin{aligned}
\alpha_{20}= & \frac{E h}{2\left(1-\nu^{2}\right)}\left[80 \frac{g}{N} \frac{1}{\left(a^{2}+b^{2}\right)}\right]\left[\frac{a^{3} m_{i} m_{j} n_{a} n_{b}}{\pi^{2}\left(m_{i}^{2}-m_{j}^{2}\right)^{2}\left(n_{a}^{2}-n_{b}^{2}\right)}\right. \\
& \left.+\frac{(1-\nu) b^{2} a m_{i} m_{j} n_{a} n_{b}}{\pi^{2}\left(n_{a}^{2}-n_{b}^{2}\right)^{2}\left(m_{i}^{2}-m_{j}^{2}\right)}\right] .
\end{aligned}
$$

In the above equation, both indices of $m, i$ and $j$ should be even or odd, one of the indices of $n, a$ or $b$ should be even, and the other one should be odd. Otherwise, this equation will be equal to zero.

\section{Biographies}

Hadi Sabermahany is a PhD scholar at Civil Engineering Department, University of Tehran, Tehran, Iran. He received his MSc from Sharif University of 
Technology, Tehran, Iran in 2015. His MSc thesis was about analysis of funicular shells.

Abolhassan Vafai is a Professor of Civil Engineering at Sharif University of Technology, Iran. He has authored/coauthored numerous papers in different field of engineering. He has also been active in the area of higher education and has delivered lectures and published papers on challenges of higher education, the future of science and technology, and human resources development.

Massood Mofid is a Professor of Civil and Structural Engineering at Sharif University of Technology, Iran. $\mathrm{He}$ received his MS and $\mathrm{PhD}$ degrees from Rise University, Houston, Texas. 